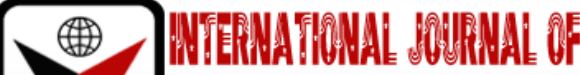

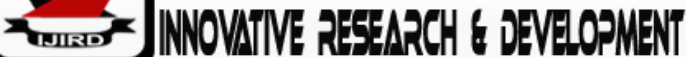

ISSN 2278-0211 (Online)

\section{Optimization of the Mechanical Properties of Kaolin-Luffa Cylindrica Filled Hybrid Composites Using Taguchi Method}

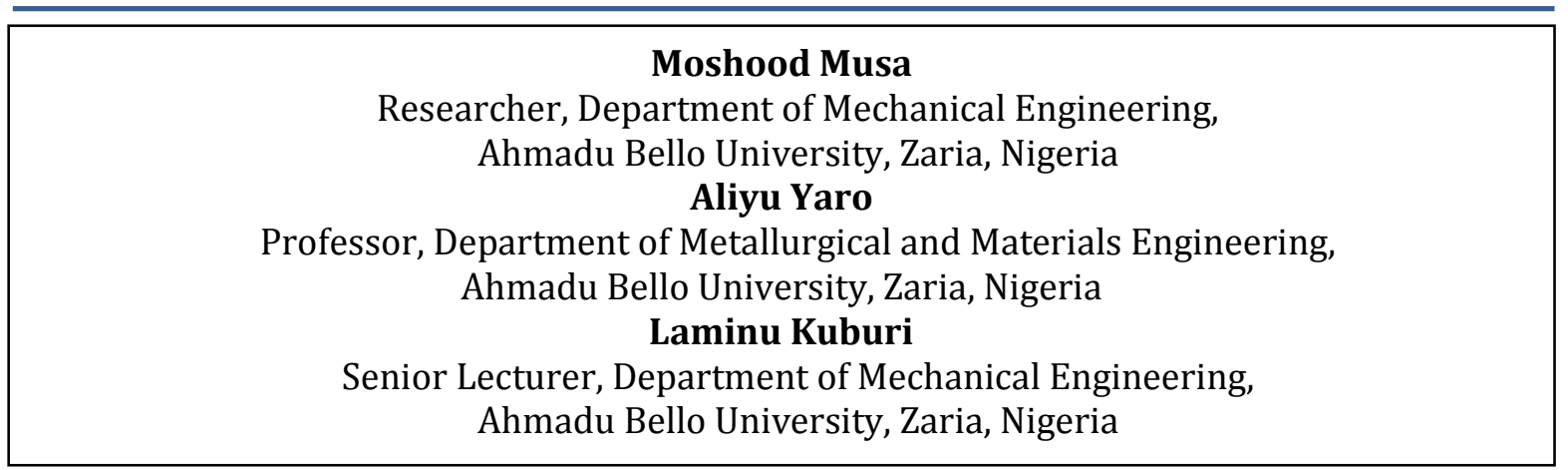

\begin{abstract}
:
Due to the density of low mass and cost are given by most fibers that are natural they have been utilized as a substitute for synthetic fibers. This investigation utilized the Taguchi technique to improve the mechanical properties of unsaturated polyester composites reinforced kaolin-luffa, to examine the process parameters optimized. The development materials that were hybrid composite were set up by hand lay-up. The optimization parameters considered are luffa fiber weight, kaolin filler weight, and kaolin filler size, each at different levels of three. Characterization of Mechanical properties, for example, tensile strength and compressive strength are selected as the objectives of consistency. Taguchi method using an orthogonal array of nine experimental runs based on L9 (33) were performed. The significant effect and data for every parameter were analyzed statistically and optimized using analysis of variance (ANOVA). The investigation was done at a confidence level of 5\% significance and it was seen that luffa fiber weight, Kaolin filler weight, and kaolin filler size significantly affect tensile strength and compressive strength. A confirmation test affirmed there were improvements in the $S / N$ ratios for both tensile and compressive strength.
\end{abstract}

Keywords: Luffa cylindrical fibre, kaolin filler, unsaturated polyester, taguchi method

\section{Introduction}

For a long time, researchers have been attempting to limit the utilization of exorbitant glass fiber, aramid fiber, or carbon fiber by using the density of lower mass and cost of most fibers that are natural and extraordinarily reduce the automobile parts. In this sense, for a few commercial vehicles and traveler vehicles, renewable fiber have been generally utilized in composite materials as load-bearing materials for interior components1-3. Natural fiber/particulate reinforced polymer matrix composites (PMCs) have surpassed synthetic fiber reinforced polymer matrix composites (PMCs) in terms of environmental friendliness, sustainability, and cost effectiveness. Natural fiber-based polymer composite materials have been used in aviation, automotive industry, sound insulation, construction, furniture, energy absorption effects, naval applications, and packaging4-5. Natural fibers such as bagasse6, flax, kenaf7, coconut husk, sisal, jute8-12, hemp13, oil palm14, etc. as reinforcement materials, perform excellently in polymer matrix composite, along these lines giving a chance of studying fibers that newly discovered. Luffacylindrica is one of the fibers that are as of now getting consideration because of its availability, inexpensive, and environmentally friendly. With a thickness of $0.56 \mathrm{~g} / \mathrm{cm} 3$, in developing lowweight composites with high strength, this fiber remains above numerous other natural fibers15. Irrespective of the interest and environmental friendliness of natural fibers, in terms of low stiffness and strength compared to synthetic fiber/filler reinforced PMCs, their applications have been limited to non-bearing utilization16. The strength and stiffness defect of bio-composites can be overwhelmed by structural configurations, particularly by substance treatment and changed fiber.

Polymer materials with high atomic weight have been perhaps the most attractive materials in recent years, owing to recent advances in technology. Among the polymer materials used in the fabrication of composite is unsaturated polyester resins. It has good chemical resistance, excellent processability, low density, and low price among the thermosetting matrix resins used in the manufacture of composite materials, so they are most commonly used in a variety of applications ${ }^{17-18}$. Although unsaturated polyester or unsaturated-based materials have many advantages, there are still 
some disadvantages to be aware of, such as low stiffness and strength, low impact resistance, and poor crack propagation resistance. To improve these disadvantages, numerous endeavors have been made, one of which is by incorporating fibers into the polymeric matrices ${ }^{19-20}$.

Over the last year, the use of natural fibers as reinforcement in polymer composites has increased. The ecofriendly and sustainable design, lightweight, low cost, high specific mechanical efficiency, and biodegradability have been the valuable features of natural fibers such as jute, luffa, sisal, silk, coir, banana. the interfacial bonding between the polymer matrix and the reinforcing fillers/fibers is a critical factor in realizing the mechanical properties of bio-based polymer composites. In order to strengthen bonding with the resin matrix, some authors have based their researched on the treatment of fillers.

In order to improve performance and reduce costs, fillers are used with different engineering polymers and applications. The various mechanical properties of the materials such as mechanical strength and modulus will increase with the use of inorganic mineral fillers in plastic resins. For the most part, the mechanical properties of molecule-filled polymer composites to a great extent rely upon the size, shape, degree of interfacial bonding between filler and matrix, and conveyance of filler particles within the polymer matrix $2^{1-25}$. Calcium carbonate, kaolin, mica, and talc are most regularly utilized as fillers to minimize production costs and improve thermoplastic properties like crystallinity, stiffness, stiffness, flexural modulus, resilience, dimensional stability, electrical conductivity, and thermal conductivity. To prepare particle composites, Al-Asade and Al-Murshdy examined the expansion of kaolin into an unsaturated polyester matrix. The expansion of 3-9\% of kaolin to the unsaturated polyester resin shows that the kaolin acts as a binder, and the subsequent composite material act as a particle strengthening agent, as a result, the unsaturated polyester mechanical properties were improved $^{26}$. Ahmed et al. studied another study of kaolin composite polyester. In this investigation, a polymer composite made of diethylene glycol and untreated kaolin (base on PET waste got from unsaturated polyester) was test. Kaolin has been processed by a chemical and thermal method. These methods affect the electrical and mechanical properties of kaolin filled polymer composites ${ }^{27}$. These findings prompted us to explore the intriguing possibility of incorporating fine micronsized kaolin particles into a luffa-reinforced polyester composite in order to investigate their impact on the mechanical properties of the composites.The hybridization of fillers with fibers has been utilized to upgrade the properties of composites. A wise choice of matrix and the reinforcing phase can result in the improvement of a composite with a combination of strength and modulus comparable to or even better than those of conventional metallic materials. Improving the properties of polymers and their composites by adding particulate filler materials in industrial and structural applications has shown great promise, and has recently attracted great attention. These have prompted us to studied the optimization of process parameters to enhance the mechanical properties of kaolin-luffacylindrica reinforced unsaturated polyester composites.Efficient tools that endorse the results of experiments are predictive modeling, Experimental design, statistical analysis, and optimization. They are utilized to perform minimum experiments by quantitatively analyzing the statistical significance of the factors, input factors variation between their respective levels, suitability of the models based on the input-output data collection and deriving model equations, and validating and confirming the adequacy. In the past, different researchers have carried out predictive modeling in process parameters and optimization of composite materials by improving the properties. Methodologies and experimental design tools mostly used as shown in the reviewed literature are Taguchi method, central composite design (CCD), finite element modeling, response surface method (RSM), box Behnken design (BBD), mixture design, factorial method, artificial neural network, etc ${ }^{28-34}$.Also, they are efficient methods for composite materials design, optimization, modeling, and statistical analysis as indicated in the results.

Previous research has investigated the effect of hybridization of luffa with certain composites of fibers/reinforcement. Sakthivel M et al. investigated the ability to use coir particulate/luffa fiber as reinforcement for a polymer such as polypropylene. They found that the addition of both lignocellulosic-based reinforcements allowed mechanical properties to be enhanced and the consistency between the two materials to be demonstrated ${ }^{35}$. Srinivasan $\mathrm{C}$. et al. investigated the impact of fiber treatment and the addition of SiO2 nanoparticles on the properties of composites ${ }^{36}$. The nature of the fiber/matrix interface was allegedly improved by fiber treatment, while the expansion of Si02 nanoparticles improved the mechanical properties. Groundnut shell particles and Luffa fiber were used to strengthen epoxy resin by Panneerdhass $\mathrm{R}$. et al. Tensile, impact, compressive, and flexural strength were observed to the volume fraction of the reinforcement. The effect of micro-fillers $\mathrm{CaC03}, \mathrm{Al} 203$, and $\mathrm{Ti02}$ on the physico-mechanical properties of luffa fiber/polyester composites was studied by Vinay et al. In the descending order of CaC03, Al203, and Ti02, it was concluded that the addition of micro-fillers affected the physico-mechanical properties of polyester composites reinforced with Luffa-fibre. On the optimization of polymer hybrid composites consisting of luffa, kaolin, and polyester, however, very little literature has been found, which offers a broad scope for the study of the optimization of different parameters for appropriate applications ${ }^{37-38}$. Mechanical characterization, processing, analysis, and optimization of a multiphase hybrid composite made of polyester resin reinforced with kaolin and luffa fiber mats were the subject of this study. In order to be strengthened, the compressive and tensile strength were chosen as mechanical properties. The strengths of these composites were tested by performing multiple experiments according to the design of experiments (DOE) and analyzed by variance analysis (ANOVA), used in the Taguchi process. These experiments were carried out in order to understand the relationship between the different controllable parameters and to identify the important parameters that affect the composite properties. By optimizing the responses, the hybrid composite material can be used in a variety of applications, including structural function, car bumpers, low-cost housing, and so on. 


\section{Experimental Detail}

\subsection{Materials and Equipment}

In this study, the matrix used is polyester resin while the reinforcement materials applied are luffa fiber and kaolin filler respectively. Locally they were all sourced. For the characterization of the composites the equipment applied is; Monsanto tens meter, Vickers hardness tester (model: MVI PC), and Charpy impact testing machine (model:412).

\subsection{Reinforcement Preparation}

Luffa fiber was treated with a $5 \% \mathrm{NaOH}$ solution at $80 \mathrm{oC}$. After the treatment, it was cleaned with distilled water and dried at room temperature for 24 hours to eliminate lignin, oil, and wax from the external surface of luffa fiber, after then it was dried at room temperature. Subsequent to drying in the sun for a couple of days, a fibrous mat of dimension $130 \mathrm{~mm}$ by $120 \mathrm{~mm}$ was cut from the external center of the luffa fruit shell, additionally placed between two wooden plates of equal height, and straightened by applying uniform compressive load with mechanical bench vices to a uniform thickness for few hours. Kaolin was utilized as a particulate filler and pure unsaturated polyester was utilized as the matrix material. Kaolin was obtained from the Department of Chemical Engineering, Ahmadu Bello University, Zaria, Nigeria. Unsaturated polyester resin, sodium hydroxide pellets, hardener, acetone, and petroleum gel were obtained from Olasco Ltd, Zaria, Nigeria.

\subsection{Composites Fabrication}

A traditional technique known as the hand lay-up method was used for the fabrication of composite. Due to its efficiency, durability, and cost-effectiveness, the hand lay-up method has been a well-known method of manufacturing natural fiber-based composites, which is economically appropriate for colleges, universities, and developing countries that are less financially funded. For the fiber-reinforced composite, fiber (luffa) was varied at weight fraction (5, 10, and 15 percent wt), while for the hybrid composite the filler (kaolin) at fraction of $6 \mathrm{wt} \%$, kaolin was kept constant, while the fiber (luffa) was varied as in the composite mono-reinforced. An electronic weighing balance is used for measuring the quantity of kaolin and the polyester matrix required and put in a glass beaker calibrated in 200 ml. In order to prevent aggregation and fast achievement and consistent filler distribution in the polyester resin matrix using a long glass rod for $10 \mathrm{~min}$, the composite mixture was stirred thoroughly. Thereafter, a disposable syringe was used to an introduced catalyst called methyl-ethyl- ketone-peroxide (MEKP) and stirred for approximately two minutes in $10 \mathrm{~mL}$ polyester to $0.2 \mathrm{~mL}$ catalyst, followed by $10 \mathrm{~mL}$ polyester to $0.1 \mathrm{~mL}$ accelerator, cobalt naphthenate accelerator was added and stirred for another two minutes. A mold release sheet was placed over the wooden molds for rapid and easy removal of composites prepared for the tensile, flexural, impact, and hardness tests specimens $(120 \times 5 \times 15 \mathrm{~mm}, 100 \times 30 \times 10 \mathrm{~mm}, 100 \times 10 \times$ $10 \mathrm{~mm}$, and $10 \times 10 \times 10 \mathrm{~mm}$ respectively) and on the inner surface of the molds, a mold release spray was applied. A small amount of the mixture was sprayed on the surface. After holding the molds on a plyboard, followed by the fiber laminate distribution to the mixture. The mixture was applied over the laminate of the fiber, and the process was repeated to get the thickness desired. An effort was made to ensure proper wetting between the matrix and the reinforcement before introducing a compressive load of $150 \mathrm{KN}$ to maintain adequate bonding and to push out trapped gases. Samples were allowed to heal for 72 hours, then samples were removed from the mold for the mechanical test. The hybrid reinforcements of three different weight fractions $(7,14$, and 21 percentage weight of the composites from the total weight) at varied ratios of mixture for the reinforcements were used (25:75, 50:50, and 75:25 ratios of kaolin filler to luffacylindrica).

\subsection{Mechanical Testing}

\subsubsection{Tensile Strength Result}

Samples of tensile tests were machined to a dumb-bell shaped of dimension $100.0 \times 15.0 \times 5.0 \mathrm{~mm}$ the unit was loaded between the upper and lower jaws of the Monsanto tensometer (type ' $W$ ') according to ASTM D638. In the device, the samples were extended until they ruptured. The breaking load and elongation values were determined accordingly. For each sample of the composite, the test was repeated three times and the average value was reported.

\subsubsection{Compressive Strength Test}

Compressive strength was performed on specimens measuring 30.0 x 30.0 x $10 \mathrm{~mm} 3$ according to ASTM D790. The universal testing machine is used to perform the compressive test with a load capacity of 50KN. After, results are analyzed to calculate the compressive strength of composite samples.

\subsubsection{Experimental Design Using Taguchi Technic (DOE)}

The design of experiments (DoE) with Taguchi methodology was used for conducting experiments to optimize the effect of kaolin filler and luffa fiber for producing the best mechanical properties (compressive strength, and tensile strength) of hybrid composites. The technique of Taguchi is an important method for analyzing and modeling the effect on production efficiency of control factors. This efficient approach employs an orthogonal array (OA) from the experimental design to test more variables in fewer experiments. The selected control factors were: Luffa fiber weight (A), Kaolin filler weight (B), and kaolin filler size (C) at three levels each, as shown in Table 1. Using L9 (27) orthogonal design, the effect of three process parameter is studied. 
In a traditional full factorial experiment, $3^{3}=27$ runs would be required to investigate three control factors at three levels, whereas Taguchi's factorial experiment method reduces the number of the trail to just 9, saving both money and time. The experimental data is then transformed into a signal-to-noise ratio (S/N). The signal is the desirable property, while the noise is the undesirable property. These ratios have three conditions: Larger is Better, Smaller is Better, and Nominal is Better. The "Larger is Better" condition can be used to measure the $\mathrm{S} / \mathrm{N}$ ratio for improving hybrid composites, as shown in equation (2). The significance and contribution of each selected parameter on the composites were then determined using ANOVA (analysis of variance).

$(\mathrm{S} / \mathrm{N})=-10 \log \left[\frac{1}{\mathrm{R}} \sum_{k=1}^{r}\left(\frac{1}{Y_{k}^{2}}\right)\right]$

Where $\mathrm{S} / \mathrm{N}=$ signal to noise ratio, $\mathrm{Y}_{\mathrm{k}}(\mathrm{k}=1,2, \ldots, \mathrm{n})$ are the values of response under trial conditions with repeated $\mathrm{R}$ times.

\begin{tabular}{|c|c|c|c|c|c|}
\hline Factor & Code & \multirow{2}{*}{ Units } & \multicolumn{3}{|c|}{ Level } \\
\cline { 4 - 6 } & & & $\mathbf{1}$ & $\mathbf{2}$ & $\mathbf{3}$ \\
\hline Luffa fiber weight & $\mathrm{A}$ & $\mathrm{wt} \%$ & 5 & 10 & 15 \\
\hline Kaolin filler weight & $\mathrm{B}$ & $\mathrm{wt} \%$ & 2 & 4 & 6 \\
\hline Kaolin filler size & $\mathrm{C}$ & $\mu \mathrm{m}$ & $-150+100$ & $-250+150$ & +250 \\
\hline
\end{tabular}

Table 1: Process Parameters and Their Levels

\begin{tabular}{|c|c|c|c|}
\hline \multirow{2}{*}{ Experiment Run } & \multicolumn{3}{|c|}{ Control Factor } \\
\cline { 2 - 4 } & A & B & $-150+100$ \\
\hline & 5 & 2 & $-250+150$ \\
\hline 3 & 5 & 4 & +250 \\
\hline 4 & 5 & 6 & $-250+150$ \\
\hline 5 & 10 & 4 & +250 \\
\hline 6 & 10 & 6 & $+150+100$ \\
\hline 7 & 10 & 250 \\
\hline 8 & 15 & 4 & $-150+100$ \\
\hline
\end{tabular}

Table 2: Taguchi $L_{9}\left(3^{3}\right)$ OA design with Control Factors

\section{Results and Discussion}

\subsection{Taguchi Analysis for Tensile Strength}

Minitab 16 software was used for Taguchi analysis, well-known statistical software explicitly utilized for designof-experiment applications. For each experiment, the sign-to-noise (S/N) ratio was calculated, which is shown in table 3 for the tensile test along with its experimental performance.

\begin{tabular}{|c|c|c|}
\hline Experiment Run & Tensile Strength (MPa) & SNRA (dB) \\
\hline 1 & 30.64 & 29.7258 \\
\hline 2 & 31.46 & 29.9552 \\
\hline 3 & 32.71 & 30.2936 \\
\hline 4 & 33.30 & 30.4489 \\
\hline 5 & 34.32 & 30.7109 \\
\hline 6 & 38.30 & 31.6640 \\
\hline 7 & 34.41 & 30.7337 \\
\hline 8 & 39.40 & 31.9099 \\
\hline 9 & 40.20 & 32.0845 \\
\hline
\end{tabular}

Table 3: Experimental Results for Tensile Strength Along with S/N Ratios

Table 4 shows the outcome of the larger-is-better characteristics as given by the response. The order of importance of tensile strength parameters is Weight of luffa fiber > kaolin filler weight > size of kaolin filler as seen in the last row of Table 4. From the main effect graph of $\mathrm{S} / \mathrm{N}$ ratio (fig. 1), the design parameter A3B3C1 for tensile strength in optimal combination can be concluded.

\begin{tabular}{|c|c|c|c|}
\hline Level & A & B & C \\
\hline 1 & 29.99 & 30.3 & 31.1 \\
\hline 2 & 30.94 & 30.86 & 30.83 \\
\hline 3 & 31.58 & 31.35 & 30.58 \\
\hline Delta & 1.58 & 1.04 & 0.52 \\
\hline Rank & 1 & 2 & 3 \\
\hline
\end{tabular}

Table 4: Response Table of S/N Ratios for Tensile Strength 


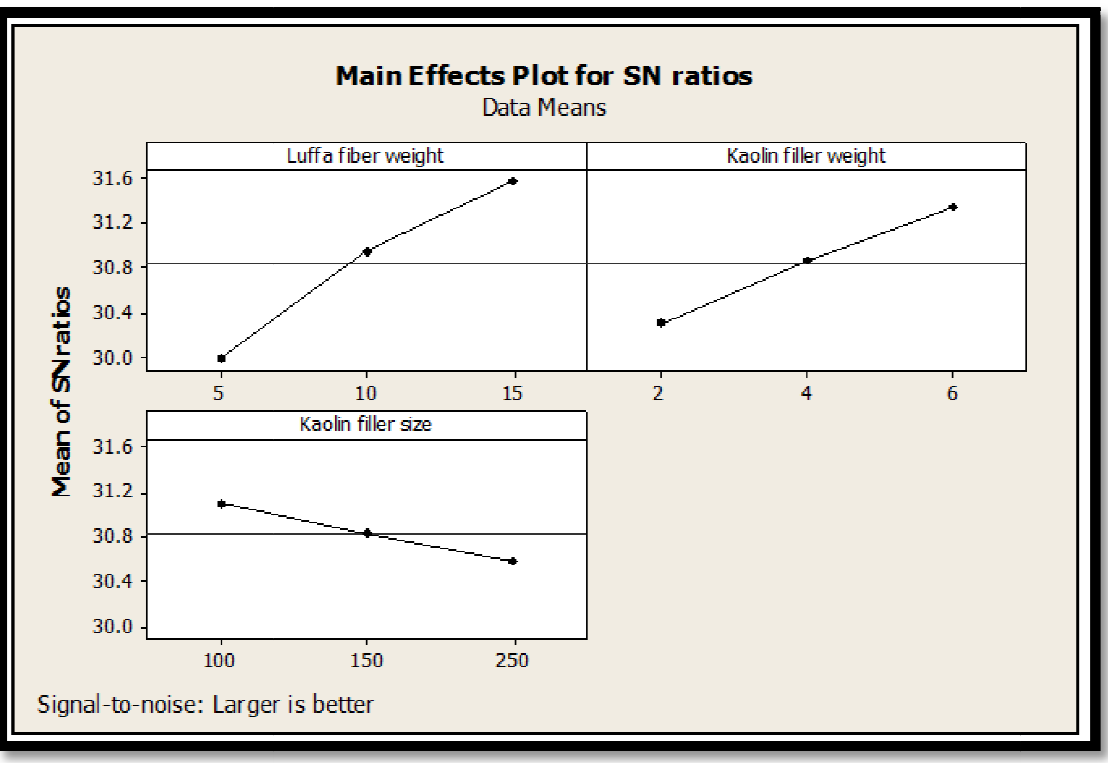

Figure 1: Main Effects Plot for S/N Ratios in Tensile Strength

\subsection{Analysis of Variance for Tensile Strength}

In evaluating the statistical significance of various factors such as luffa weight fiber, kaolin filler weight, and kaolin filler size on tensile strength, the experimental result is subjected to Analysis of Variance (ANOVA). The ANOVA results for tensile strength are shown in Table 5. For a 5\% confidence level of importance, this study is performed. The primary effects are highly important, according to the table's last column. From Table 5, one can observe that luffa fiber weight ( $\mathrm{p}=$ 0.004), Kaolin filler weight ( $p=0.009)$, and kaolin filler size $(p=0.036)$ have great influence on tensile strength. At a level of confidence of significance of $5 \%$, it was observed that significant factors for tensile strength are luffa fiber weight, Kaolin filler weight, and kaolin filler respectively.

In order to verify the analysis (table 6), validation tests were performed by comparing real values and predicted values. For tensile strength, the increase in the $\mathrm{S} / \mathrm{N}$ ratio was found to be $1.6399 \mathrm{~dB}$.

\begin{tabular}{|c|c|c|c|c|c|c|}
\hline Source & DF & Seq SS & Adj SS & Adj MS & F & P \\
\hline A & 2 & 3.81569 & 3.81569 & 1.90784 & 253.73 & 0.004 \\
\hline B & 2 & 1.63899 & 1.63899 & 0.81950 & 109.01 & 0.009 \\
\hline C & 2 & 0.40655 & 0.40655 & 0.20327 & 27.04 & 0.036 \\
\hline Error & 2 & 0.01503 & 0.01503 & 0.00752 & & \\
\hline Total & 8 & 5.87626 & & & & \\
\hline
\end{tabular}

Table 5: ANOVA Results for Tensile Strength Value

Adj MS, extra mean square; Adj SS, extra sum squares; DF, degree of freedom; F, F-test percentage contribution; Seq SS, sequential sum squares

\begin{tabular}{|c|c|c|c|}
\hline Parameter & Mean Parameter & \multicolumn{2}{|c|}{ Optimal Parameter } \\
\hline & & \multicolumn{2}{|c|}{ A3B3C1 } \\
\hline & A2B2C3 & 41.2444 & 42.4364 \\
\hline Strength & 34.32 & 32.3502 & 32.5548 \\
\hline S/N Ratio & 30.7109 &
\end{tabular}

Table 6: Confirmation Table for Tensile Strength

\subsection{Taguchi Analysis for Compressive Strength}

The study was conducted using Minitab 16, a popular statistical software primarily used for design-of-experiment applications. For the compression test, the signal-to-noise $(\mathrm{S} / \mathrm{N})$ ratio was calculated, as well as the experimental results, which are described in Table 7. 


\begin{tabular}{|c|c|c|}
\hline Experiment Run & Compressive Strength (MPa) & S/N Ratio (dB) \\
\hline 1 & 73.0 & 37.2665 \\
\hline 2 & 94.5 & 39.5086 \\
\hline 3 & 76.7 & 37.6959 \\
\hline 4 & 121.0 & 41.6557 \\
\hline 5 & 119.7 & 41.5619 \\
\hline 6 & 81.0 & 38.1697 \\
\hline 7 & 67.1 & 36.5345 \\
\hline 8 & 52.4 & 34.3866 \\
\hline 9 & 54.7 & 34.7597 \\
\hline
\end{tabular}

Table 8 shows the result obtained from the larger-is-better characteristics as provided by the response. Luffa fiber weight > kaolin filler size > kaolin filler weight as shown in the last row of Table 8 is the order of importance of the compressive strength parameters. It can be concluded from the main effect graph of the S/N ratio (fig. 2) that the design parameter is A2B2C2 for the optimal combination of compressive strength.

\begin{tabular}{|c|c|c|c|}
\hline Level & A & B & C \\
\hline 1 & 38.16 & 38.49 & 36.61 \\
\hline 2 & 40.46 & 38.49 & 38.64 \\
\hline 3 & 35.23 & 36.88 & 38.60 \\
\hline Delta & 5.24 & 1.61 & 2.03 \\
\hline Rank & 1 & 3 & 2 \\
\hline
\end{tabular}

Table 8: Response Table for Compressive Strength for S/N Ratios

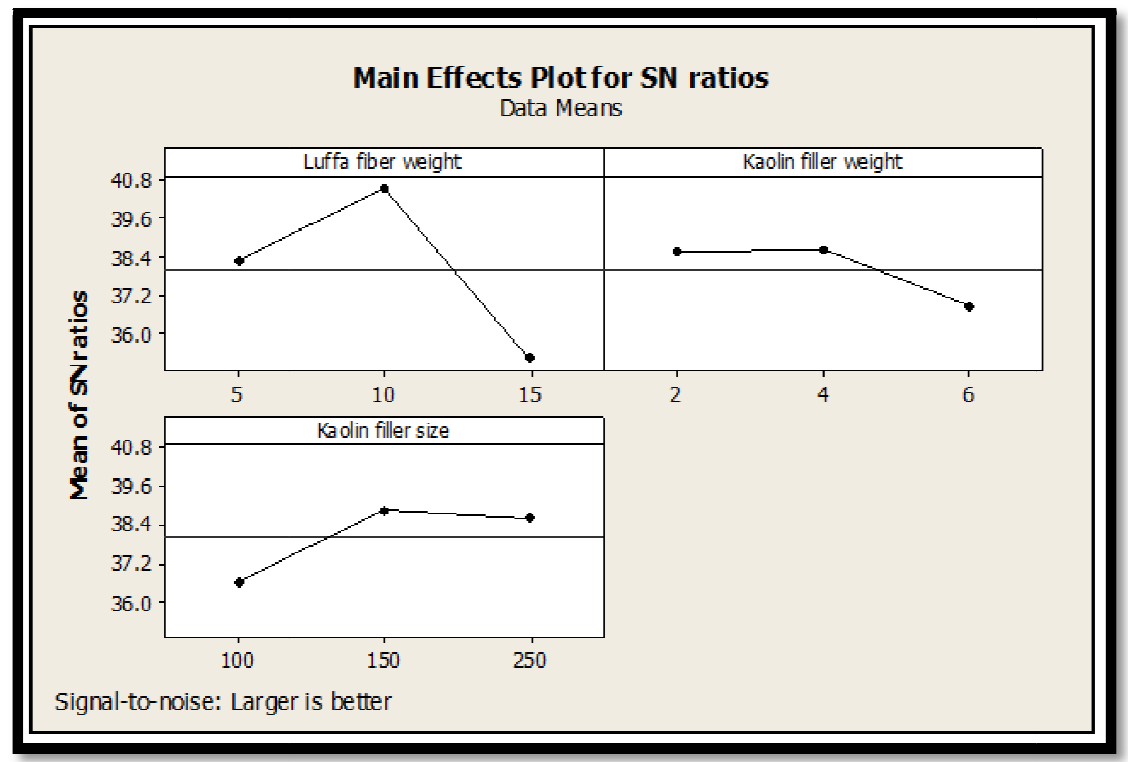

Figure 2: Main Effects Plot for S/N Ratios for Compressive Strength

\subsection{Analysis of Variance for Compressive Strength}

In evaluating the statistical significance of various factors such as luffa weight fiber, kaolin filler weight, and kaolin filler size on compressive strength, the experimental results are subjected to Analysis of Variance (ANOVA). The ANOVA results for compressive strength are shown in Table 9. For a 5\% confidence level of importance, this study is performed. The primary effects are highly important, according to the table's last column. Table 9 shows that Luffa fiber weight ( $\mathrm{p}=$ 0.003), Kaolin filler weight $(\mathrm{p}=0.016)$, and kaolin filler size $(\mathrm{p}=0.012)$ have significant impact on compressive strength. Luffa fiber weight, Kaolin filler weight, and kaolin filler size were found to be the major factor for compressive strength at a $5 \%$ confidence level of significance.

In order to validate the analysis (table 10), confirmation tests were performed by evaluating the actual and estimated values $4.5996 \mathrm{~dB}$ was found to be the increase in the $\mathrm{S} / \mathrm{N}$ ratio for compressive strength. 


\begin{tabular}{|c|c|c|c|c|c|c|}
\hline Source & DF & Seq SS & Adj SS & Adj MS & F & P \\
\hline A & 2 & 3629.17 & 3629.17 & 1814.58 & 377.25 & $\mathbf{0 . 0 0 3}$ \\
\hline B & 2 & 593.29 & 593.29 & 296.64 & 61.67 & $\mathbf{0 . 0 1 6}$ \\
\hline C & 2 & 819.53 & 819.53 & 409.76 & 85.19 & $\mathbf{0 . 0 1 2}$ \\
\hline Error & 2 & 9.62 & 9.62 & 4.81 & & \\
\hline Total & 8 & 5051.60 & & & & \\
\hline
\end{tabular}

Table 9: ANOVA Results for Compressive Test

Adj MS, extra mean square; Adj SS, extra sum squares; DF, degree of freedom; F, F-test percentage contribution; Seq SS, sequential sum squares

\begin{tabular}{|c|c|c|c|}
\hline Parameter & Mean Parameter & \multicolumn{2}{|c|}{ Optimal Parameter } \\
\hline & & \multicolumn{3}{|c|}{ Experimental } & Predicted \\
\hline & A1B1C1 & \multicolumn{3}{|c|}{ A3BC1 } \\
\hline Strength & 73.0 & 123.966 & 121.7 \\
\hline S/N Ratio & 37.2665 & 41.8661 & 41.6919 \\
\hline
\end{tabular}

Table 10: Confirmation Table for Compressive Strength

\section{Conclusions}

Optimizations of tensile and compressive strength of kaolin-luffacylindrica filled hybrid composites were conducted.

The experiment leads us to the following conclusions obtained from this study:

1. The efficient development of a new class of polyester matrix composites reinforced with luffa fiber and kaolin particulate is supported by a simple hand lay-up technique.

2. With Taguchi analysis, composite optimization is done and the response table shows that the weight of the luffa fiber is the primary factor for tensile and compressive strength. It can be concluded from ANOVA findings that the weight of luffa fiber, the weight of kaolin filler, and the size of kaolin filler at a $5 \%$ confidence level of significance were significant factors in the composite's strength. Confirmation tests were also performed to verify the results, which revealed an increase in the $\mathrm{S} / \mathrm{N}$ ratio. In tensile strength, the $\mathrm{S} / \mathrm{N}$ ratio improved by $1.6399 \mathrm{~dB}$, and in compressive strength, it improved by $4.5996 \mathrm{~dB}$.

3. This research can be extended to new hybrid composites with different filler-fiber combinations in the future, and the results can be analyzed in the same way.

\section{Funding}

This work did not receive any special grant from any federal, commercial or non-profit funding agency

\section{References}

i. Holbery J. and Houston D. Natural-Fiber Reinforced Polymer Composites in Automotive Applications. JOM 2006; 58: 80-86.

ii. Mohanty AK, Misra M and Drzal LT. Natural Fibers, Biopolymers, and Biocomposites. CRC Press, Taylor \& Francis Group, Boca Raton, 2005.

iii. Farag MM. Quantitative Methods of Materials Substitution: Application to Automotive Components. Materials \& Design. 2009; 29: 374-378.

iv. El-Tayeb NS. Abrasive Wear Performance of Untreated SCF Reinforced Polymer Composite. J Mater Process Technol 2008; 206: 305-314.

v. Mohanta $\mathrm{N}$ and Acharya SK. Mechanical and tribological performance of LuffaCylindricafibre - reinforced epoxy composite. BioResources 2015; 10(4):8364-8377

vi. Suresha B, Chandramohanm G, Samapthkumaran, P et al. Three-Body Abrasive Wear Behaviour of Carbon and Glass Fiber Reinforced Epoxy Composites. Mater SciEng 2007; 443:285-291.

vii. Chirayil CJ, Mathew L, Hassan PA et al. (2014). Rheological behaviour of nanocellulosereinforcedunsaturated polyester nanocomposites. Int J Bio Macro 2014; 69: 274-281.

viii. XuLandLeeLJ.Kinetic analysis and mechanical properties of nanoclay reinforced unsaturated polyester (UP) resins cured at low temperatures.PolyEngSci 2005; 45(4): 496-509.

ix. Vera-AgulloJ, Gloria-PereiraA, Varela-RizoH et al. Comparative study of the dispersion and functional properties of multiwall carbon nanotubes and helical-ribbon carbon nano fibers in polyester nanocomposites.ComposSci Technol2009; 69(10):1521-1532.

$\mathrm{x}$. JohnKandNaiduSV.Tensile properties of unsaturated polyester-based sisal fiber-glass fiber hybrid composites. J ReinfPlast Compos 2004; 23(17) 1815-1819.

xi. SinghaAS and Thakur VK.Effect of fibre loading on urea Formaldehyde based green Composites. J poly iran 2008; 17: 861-873.

xii. CecilliaMA, HiliarioCMO and CornellisVHJ. Thermal and mechanical behavior of sisal/phenolic composites. Compos SciTechnol 2012; 43: 2843-2850.

xiii. NishinoT, HiraoK, KoteraM, NakamaeK et al. Kenaf reinforced biodegradable composite. Compos. Sci. Technol. 2003;63:1281-1286. 
xiv. De SousaMV, MonteiroSN and D'AlmeidaJRM. Evaluation of pre-treatment, size and molding pressure on flexural mechanical behavior of chopped bagasse polyester composites. Polym Test 2004; 23:253-258.

xv. GowdaTM, NaibuACB and ChhayaR. Some mechanical properties of untreated jute fabric-reinforced polyester composites. Compos 1999; 30: 277-284.

xvi. RayD, SarkarBK and RanaAK. The mechanical properties of vinylester resin matrix composites reinforced with alkali-treated jute fibres. Compos 2011; 32: 119-127.

xvii. Gassan J. A study of fiber and interface parameters affecting the fatigue behavior of natural fiber composites, Compos 2002; 33: 369-374.

xviii. KhanMA, HaqueN and KafiAA et al. Jute reinforced polymer composite by gamma radiation: effect of surface treatment with UV radiation. PolymPlastTechnol Eng2006; 45: 607-613.

xix. KhanMA and HassanMM. Effect of $\gamma$-aminopropyltrimethoxysilane on the performance of jute-polycar-bonate composite. J ApplPolymSci 2006; 100: 4142-4147.

xx. KhanMA,HassanMM and Drzal LT. Effect of 2-hydroxyethyl mathacrylate (HEMA) on the mechanical and thermal properties of jute-polycarbonate composites. Compos2005;36: 71-81.

xxi. KellerA, Compounding and mechanical properties of biodegradable hemp fiber composites, Compos SciTechnol 2003; 63: 1307-1316

xxii. WollerdorferM and Bader H. Influence of natural fibers on the mechanical properties of biodegradable polymers. Ind Crops Prod 1998; 8: 105-112.

xxiii. Vignesh K, Manikandan T, MadhankumarAet al. Investigation on tensile and flexural strength of KOH treated ridge gourd fiber-polyester resin composite. Int J Recent Innov Trends ComputCommun 2015; 3(3):14931496.

xxiv. Sakthivel M, Vijayakumar S and Ramesh S. Production and characterization of Luffa/coir reinforced polypropylene composite. Procedia Mater Sci 2014; 5:739-745.

xxv. Srinivasan C, Sathish S and Vignesh K. Mechanical properties of chemically treated LuffaAegyptiaca fiber reinforced epoxy matrix composites. Int J Sci Res Manag (IJSRM) 2014; 2(10):1515-1524

xxvi. Guo QB, Lau KT, Rong MZ et al. Optimization of tribological and mechanical properties of epoxy through hybrid filling. Wear 2010; 269(1-2): 13-20.

xxvii. Panneerdhass R, Gnanavelbabu A, Rajkumar K. Mechanical properties of Luffa Fiber and ground nut reinforced epoxy polymer hybrid composites. Procedia Eng 2014; 97:2042-2051.

xxviii. Okafor EC, Ihueze CC and Nwigbo SC. Optimization of hardness strengths response of plantain fibers reinforced polyester matrix composites (PFRP) applying Taguchi robust design. IJE Trans A: 2013; 26: 1-11.

xxix. Lopez RH, Luersen MA and Cursi JES. Optimization of hybrid laminated composites using a genetic algorithm. J BrazSocMechSciEng 2009; 31: 269-278.

xxx. $\quad$ Ross P J. Taguchi techniques for quality engineering. New York: McGraw-Hill,1998.

xxxi. LindmanH.Analysis of variance in experimental design. NewYork: Springer-Verlag, 1992.

xxxii. Prabu A, Uthayakumar M and Manikandan V. Investigation of the mechanical properties on red mud filled polyester banana composites using grey relational technique. Mater Phy and Mech 2012; 14: 57-63.

xxxiii. $\quad$ Ross PJ. Taguchi technique for quality engineering. Singapore: McGRAW-Hill 1996.

xxxiv. Roy RK.A Primer on the Taguchi Method. Van Nostrand Reinhold, New York, NY, USA, 1990.

xxxv. Obiorah SM, Fayomi SI, Okonkwo EG, et al. Effect of luffa cylindrical fiber and particulate on the mechanical properties of epoxy. Int J AdvmanufTechnol 2019.

xxxvi. Gupta A, Singh H and Walia RS. Hybrid filler composition optimization for tensile strength of jute fiberreinforced polymer composite. Bull. Mater. Sci. 2016; 39(5):1223-1231.

xxxvii. Ahmed KS, Mallinatha V, and Amith SJ. Effect of ceramic fillers on mechanical properties of woven jute fabric reinforced epoxy composites.JReinfPlast Compos 2011; 30(15) 1315-1326.

xxxviii. Krishnudu DM, Sreeramulu D and Reddy PV. Optimization the mechanical properties of coir-luffa cylindrical filled hybrid composites by using taguchi method. AIP Conference. Proceedings 2018. 